\title{
Transplantation of amniotic membrane and limbal autograft for patients with recurrent pterygium associated with symblepharon
}

\author{
Jun Shimazaki, Naoshi Shinozaki, Kazuo Tsubota
}

\begin{abstract}
Aim-Treatment of recurrent pterygium associated with symblepharon requires both suppression of fibrosis and reconstruction of limbal barrier. To achieve this, human amniotic membrane was transplanted and limbal autografts performed.

Methods-Four patients with severe symblepharon resulting from multiple surgeries for pterygium were treated. Human amniotic membrane was obtained at caesarean section and preserved until surgery. After excision of the fibrous tissues, the amniotic membrane was placed on the sclera, and a limbal autograft transplantation was performed using limbal tissues taken from the affected eye.

Results-Recurrence of symblepharon was not observed in any of the patients and significant suppression of the subconjunctival fibrosis was achieved. Ocular movement improved in all cases. Complete remission of pterygium regrowth occurred in three cases, and a slight (about 1 $\mathrm{mm}$ ) recurrence occurred in one case. The limbal donor site showed the presence of mild depressions without the formation of pseudopterygium.

Conclusion-Transplantation of human amniotic membrane with a limbal autograft appears to be a promising surgical treatment for reconstructing the ocular surface in patients with recurrent pterygium associated with symblepharon. (Br F Ophthalmol 1998;82:235-240)
\end{abstract}

Treatment of recurrent pterygium

Although many surgical approaches have been developed, recurrent pterygium presents a significant surgical problem. Conjunctival fornix shortening or symblepharon caused by multiple surgeries is especially challenging. Repeated surgical interventions in the limbal area cause severe barrier function destruction, and simple excision results in severe fibrous tissue regrowth. To treat this complicated disorder, both suppression of the subconjunctival fibrosis and the reconstruction of limbal barrier are required. In order to restore barrier function, conjunctival transplantation, ${ }^{12}$ keratoepithelioplasty, ${ }^{3}$ lamellar keratoplasty, ${ }^{4}$ and limbal autograft transplantation ${ }^{56}$ have been performed. Although these techniques have been shown to be useful for the treatment of recurrent pterygium, they do not suppress subconjunctival fibrosis. ${ }^{7}$ Therefore, these techniques are usually inadequate for cases with severe fibrosis such as those presenting with symblepharon formation.

Antimetabolites such as 5-fluorouracil (5FU) and mitomycin C (MMC) have powerful antifibrosis effects, and both intraoperative and postoperative application of these drugs have been shown to be useful for the treatment of pterygium..$^{8-12}$ However, specific indications, treatment regimens, and delivery systems have not been established. Improper use of antimetabolites can cause severe complications, including delayed epithelialisation and scleral ulceration. ${ }^{13} 14$

Transplantation of amniotic membrane Amniotic membrane has been used as a surgical material since the 1940 s, and the membrane has been shown to have a strong antiadhesive effect. ${ }^{15-17}$ Amniotic membrane has a thick collagen layer and an overlying basement membrane with a single layer of epithelium. The use of amniotic membranes has been suggested as a replacement for a function substrate, ${ }^{1518}$ as the presence of normal substrate is essential for normal proliferation and differentiation of epithelial cells. This is also true in the cornea, since the corneal epithelium and underlying stromal cells have been shown to interact intimately through various cytokines. ${ }^{19}$ Kim and Tseng used preserved human amniotic membrane to supply a normal substrate in rabbit chemical burn models, and they were able to successfully reconstruct the ocular surface.$^{20}$ In the present series, we used amniotic membrane, the innermost layer of the fetal membrane, for the treatment of recurrent pterygium associated with symblepharon formation. After the removal of proliferative tissue, amniotic membrane was placed on the sclera. Then a limbal autograft transplantation was performed. We describe the method and present detailed results in four patients.

\section{Subjects and methods}

PATIENTS

Four eyes of four patients (mean age 53.5 years) with recurrent pterygium were treated by transplantation of amniotic membrane and a limbal autograft (Table 1). These eyes had been treated by conventional surgeries without success, and ocular movements were severely restricted due to symblepharon or subconjunctival fibrosis around the medial rectus muscle. Two eyes (cases 1 and 2) had pterygium that extended to the central cornea. The mean follow up time was 59.8 weeks (range 16-96 weeks). 
PREPARATION OF AMNIOTIC MEMBRANE

Amniotic membrane attached to the placenta was obtained at the time of caesarean section from mothers seronegative for hepatitis B virus, hepatitis $\mathrm{C}$ virus, syphilis, and human immunodeficiency virus. The following procedures were performed under sterile conditions: After washing with physiological saline or $0.01 \mathrm{M}$ PBS containing $100 \mathrm{mg}$ of dibekacin sulphate (Panimycin, Meiji Pharmaceutical Co, Tokyo, Japan), the amniotic membrane with the chorion was separated from other uterus tissue by blunt dissection. The membrane was then cut into pieces measuring about $5 \times 5 \mathrm{~cm}$ and rinsed three times in $0.01 \mathrm{M}$ PBS. Each piece was rinsed in $0.5 \mathrm{M}$ DMSO dissolved in PBS, then in $1.0 \mathrm{M}$ and $1.5 \mathrm{M}$ DMSO in PBS, for 5 minutes each. The membrane was placed in a plastic container, and preserved at $-80^{\circ} \mathrm{C}$ until use. The container with amniotic membrane was thawed at room temperature preoperatively, and the membrane was rinsed three times in saline, then once in saline containing $100 \mathrm{mg}$ of dibekacin sulphate. At the time of surgery, the amniotic membrane was separated bluntly from the underlying chorion with forceps.

\section{SURGICAL PROCEDURES}

Surgery was performed under retrobulbar anaesthesia using $2 \%$ lignocaine with 1:100 000 noradrenaline (Xylocaine E, Fujisawa Pharmaceutical Co, Osaka, Japan). Firstly, the head of the pterygium was removed as bluntly as possible to avoid injuring the underlying corneal stroma. A superficial keratectomy was performed when stromal opacity was dense enough to impair visual rehabilitation. All subconjunctival fibrosis was excised, and the sclera was exposed (Fig 1A). Care was taken not to injure the medial rectus muscle. Amniotic membrane was placed on the exposed sclera, epithelial side up, and secured to the sclera with 9-0 silk sutures (Fig 1B). The epithelial side of the amniotic membrane was determined by identifying the opposite side to which the chorion was attached. Limbal autograft tissue taken from the 12 o'clock position of the affected eye included bulbar conjunctiva and thin corneal stroma about 4 $\mathrm{mm}$ in width (Fig 1C). Care was taken to leave Tenon's capsule intact. The limbal tissue was transferred to the area of excision, placed and secured with 10-0 nylon sutures. Then four to six 9-0 silk sutures were placed in the conjunctival portion of the graft (Fig 1D), penetrating both the underlying amniotic membrane and the sclera. Figure $1 \mathrm{E}$ is a scheme of the surgical steps. After the surgery, a therapeutic soft contact lens was put in place, and $100 \mathrm{mg}$ of dibekacin sulphate and $10 \mathrm{mg}$ of dexamethasone were injected subconjunctivally. Postoperatively, $0.1 \%$ dexamethasone eyedrops (Sanbetason, Santen Pharmaceutical Co, Osaka, Japan) and $0.3 \%$ ofloxacin eyedrops (Tarivid, Santen) were used five times a day. They were subsequently replaced with $0.1 \%$ fluorometholone eyedrops (Flumetholon, Santen) three times daily for the next few months.

\section{Results}

Within 1 week following surgery, the surface of the cornea and amniotic membrane was re-epithelialised in all four cases. No amniotic membranes were rejected, and subconjunctival fibrosis was limited to be mild in three eyes, and slight fibrosis noted in the fourth eye (case 4). One eye (case 3) showed a recurrence of pterygium, with approximately $1 \mathrm{~mm}$ invasion into the cornea, but remained stable for 12 months with the instillation of steroid eyedrops. Symblepharon was successfully treated in all cases to the point that the conjunctival fornix was re-established. As a result, marked improvements in a diplopia were noted in all cases. Although a mild subepithelial opacity in the cornea persisted in one eye (case 2), significant improvement in corrected visual acuity was noted in one eye (case 1). Thinning of the stroma at donor sites to about $20-30 \%$ of normal thickness occurred in all cases; however, no pseudopterygium formed. Specular micrographs of the central corneal epithelium taken postoperatively revealed normal arrangement of the epithelial cells. The details of each case are presented below.

\section{CASE 1}

A 62 year old woman was referred to us in November 1994 for recurrent pterygium in her left eye. She had undergone pterygium excision 10 years earlier, but the condition recurred after 3 years. The pterygium extended from an inferior nasal lesion to the central cornea, so that corrected visual acuity in the eye was $20 / 200$. There was severe symblepharon, and the inferior punctum was dislocated temporally (Fig 2A). Abduction of the left eye was severely impaired. Excision of both the pterygium and subconjunctival fibrosis, combined with amniotic membrane transplantation and a limbal autograft, was performed in December 1994. The surface of the cornea and the amniotic membrane were promptly epithelialised, with no recurrence of pterygium. One year after surgery, corrected visual acuity

Table 1 Patient profiles and surgical results

\begin{tabular}{lllllllllll}
\hline Case & $\begin{array}{l}\text { Age } \\
\text { (years) }\end{array}$ & Sex & $\begin{array}{l}\text { Number of } \\
\text { previous } \\
\text { surgeries }\end{array}$ & $\begin{array}{l}\text { Preop } \\
\text { diplopia }\end{array}$ & Symblepharon & $\begin{array}{l}\text { Preop } \\
\text { VA }\end{array}$ & $\begin{array}{l}\text { Postop } \\
\text { VA }\end{array}$ & $\begin{array}{l}\text { Postop } \\
\text { diplopia }\end{array}$ & Recurrence & $\begin{array}{l}\text { Follow up } \\
\text { (weeks) }\end{array}$ \\
\hline 1 & 62 & F & 1 & ++ & + & $+20 / 200$ & $20 / 30$ & + & - & 5 \\
2 & 66 & M & 2 & ++ & + & $20 / 20$ & $20 / 15$ & - & - & 16 \\
3 & 56 & F & 2 & + & + & $20 / 25$ & $20 / 25$ & + & + (about & 96 \\
4 & 50 & F & 7 & ++ & + & $20 / 15$ & $20 / 15$ & $+/-$ & - & 72 \\
\hline
\end{tabular}

^Diplopia was graded as follows: +++ present in all fields, ++ present within central 30 degrees, but not in all fields, + present outside central 30 degrees, - not present.

Preop $=$ preoperative, postop $=$ postoperative, $\mathrm{VA}=$ best corrected visual acuity. 
recovered to $20 / 30$, and there was only mild fibrosis in the affected area (Fig 2B). The cornea was clear, with minimal surface irregularity. A deep inferior fornix formed, and ocular movement returned to normal.

CASE 2

A 66 year old man had undergone pterygium excision in his right eye twice. Both procedures were followed by recurrence associated with symblepharon formation. On first examination in March 1995, vision in his right eye was 20/20. A recurrent pterygium extended from the inferior nasal bulbar conjunctiva to the paracentral cornea (Fig 2C). A stalk-like adhesion from the medial lower eyelid to the paracentral cornea was formed, so that ocular movement was severely impaired. Pterygium excision, lysis of the symblepharon, and amniotic membrane transplantation with a limbal autograft were performed in April 1995. To avoid postoperative fornix shortening, a silicone sponge $3 \mathrm{~mm}$ in diameter was placed in the inferior fornix and secured to the lid with two mattress 6-0 nylon sutures. Although stromal opacity at the peripheral cornea persisted, there was no postoperative recurrence of pterygium. Four months later, vision in the patient's right eye was $20 / 15$, and there was no regrowth of subconjunctival fibrosis (Fig 2D). Eye movement completely returned to normal.

\section{CASE 3}

A 56 year old woman had recurrent pterygium in her right eye. She had undergone simple pterygium excision 10 years earlier and free conjunctival transplantation 16 months earlier. Massive subconjunctival fibrosis was formed between the nasal lid and the cornea so that abduction of the eye was severely limited (Fig
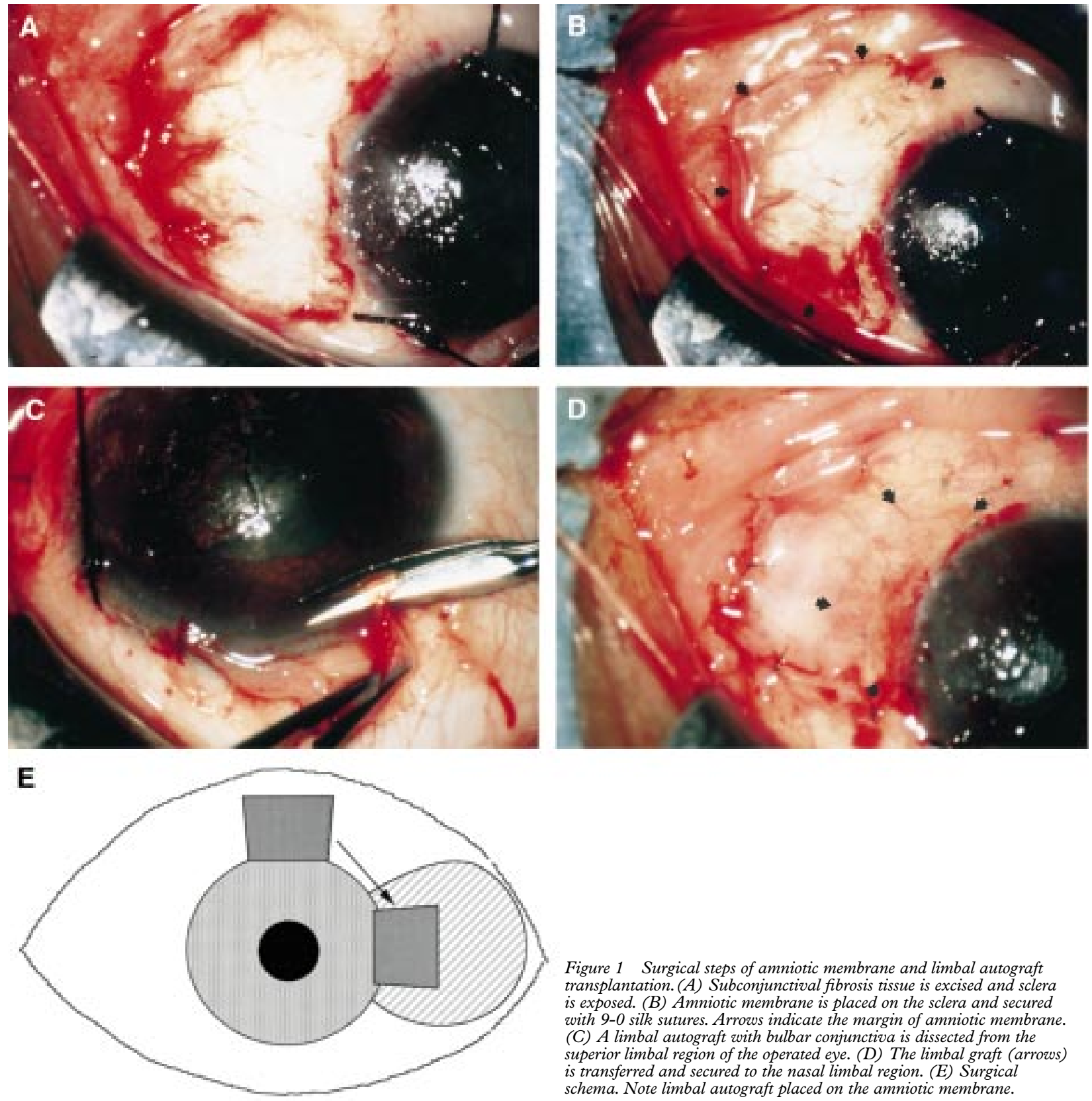

Figure 1 Surgical steps of amniotic membrane and limbal autograft transplantation. (A) Subconjunctival fibrosis tissue is excised and sclera is exposed. (B) Amniotic membrane is placed on the sclera and secured with 9-0 silk sutures. Arrows indicate the margin of amniotic membrane. (C) A limbal autograft with bulbar conjunctiva is dissected from the superior limbal region of the operated eye. (D) The limbal graft (arrows) is transferred and secured to the nasal limbal region. (E) Surgical schema. Note limbal autograft placed on the amniotic membrane. 
2E). Removal of subconjunctival fibrosis, the lysis of symblepharon, transplantation of amniotic membrane, and a limbal autograft were performed, and a silicone sponge was placed in the inferior fornix without complications. The silicone sponge was removed 3 weeks later. Slight recurrence of pterygium developed 4 months later, without formation of subconjunctival fibrosis or symblepharon. By frequent instillation of steroid eyedrops $(0.1 \%$ dexamethasone five times a day, tapered to $0.1 \%$
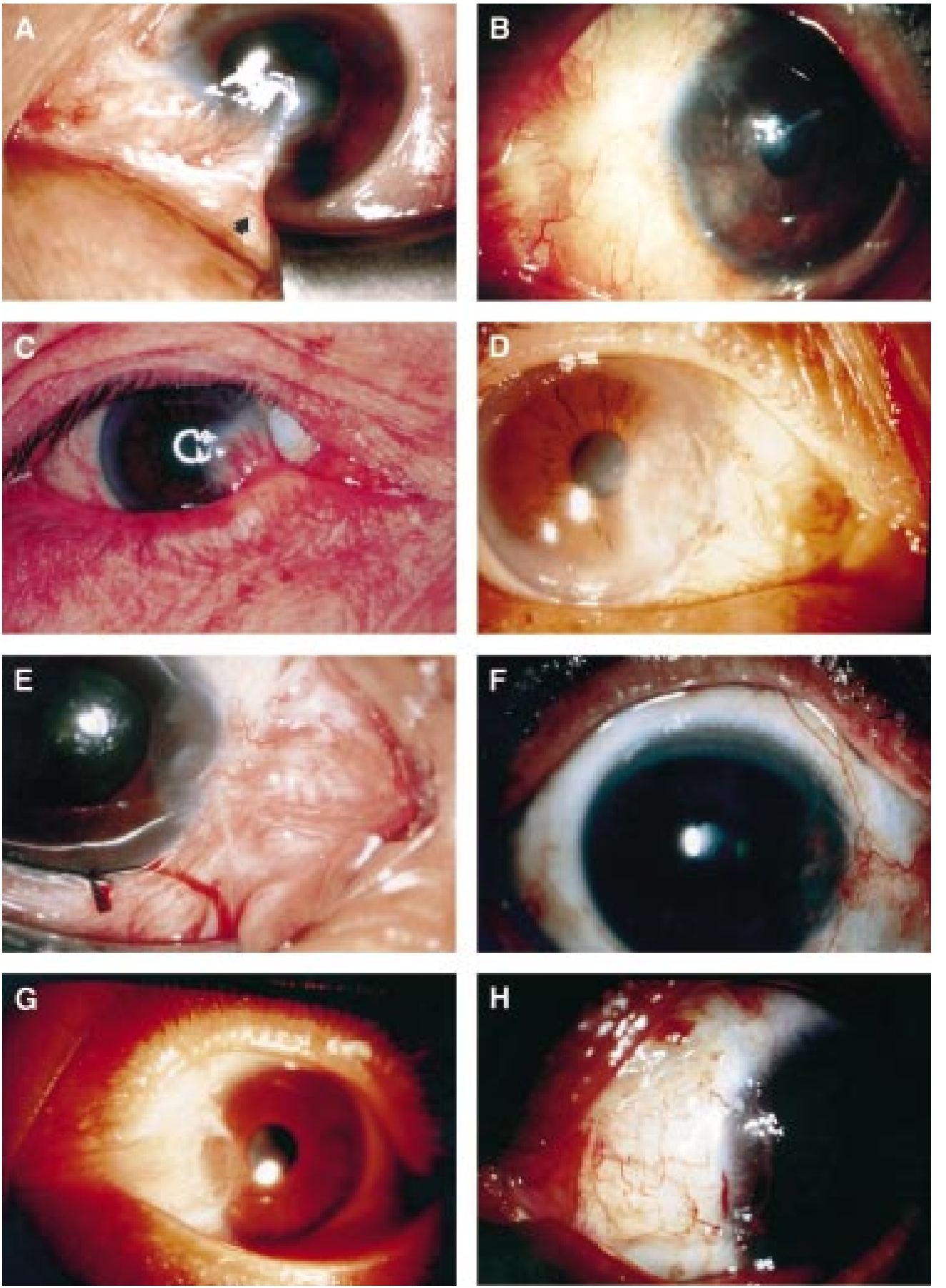

Figure 2 (A) Preoperative appearance of case 1. Severe symblepharon is formed. Inferior punctum is dislocated (arrow). (B) Postoperatively, symblepharon is lysed almost completely, and the central cornea is clear. (C) Case 2. A stalk-shaped symblepharon is seen preoperatively. (D) Symblepharon is lysed, and no recurrence of pterygium is noted. (E) Case 3. Severe subconjunctival fibrosis at the nasal region is recognised. (F) Postoperatively, the nasal conjunctiva is flat without fibrous tissue regrowth. $(G)$ Case 4. Massive fibrosis is formed around the medial muscle. (H) Adhesion between medial muscle and canthus is lysed after the surgery. Note persistence of slight subconjunctival fibrosis at the $10 o^{\circ}$ 'clock position.

fluorometholone three times a day), no further invasion of the lesion occurred (Fig $2 \mathrm{~F}$ ).

CASE 4 surgeries for pterygium in her left eye including simple excision, conjunctival transplantation, the postoperative use of 5-fluorouracil eyedrops, and lamellar keratoplasty. Severe subconjunctival fibrosis was observed around the medial rectus muscle. Although invasion of
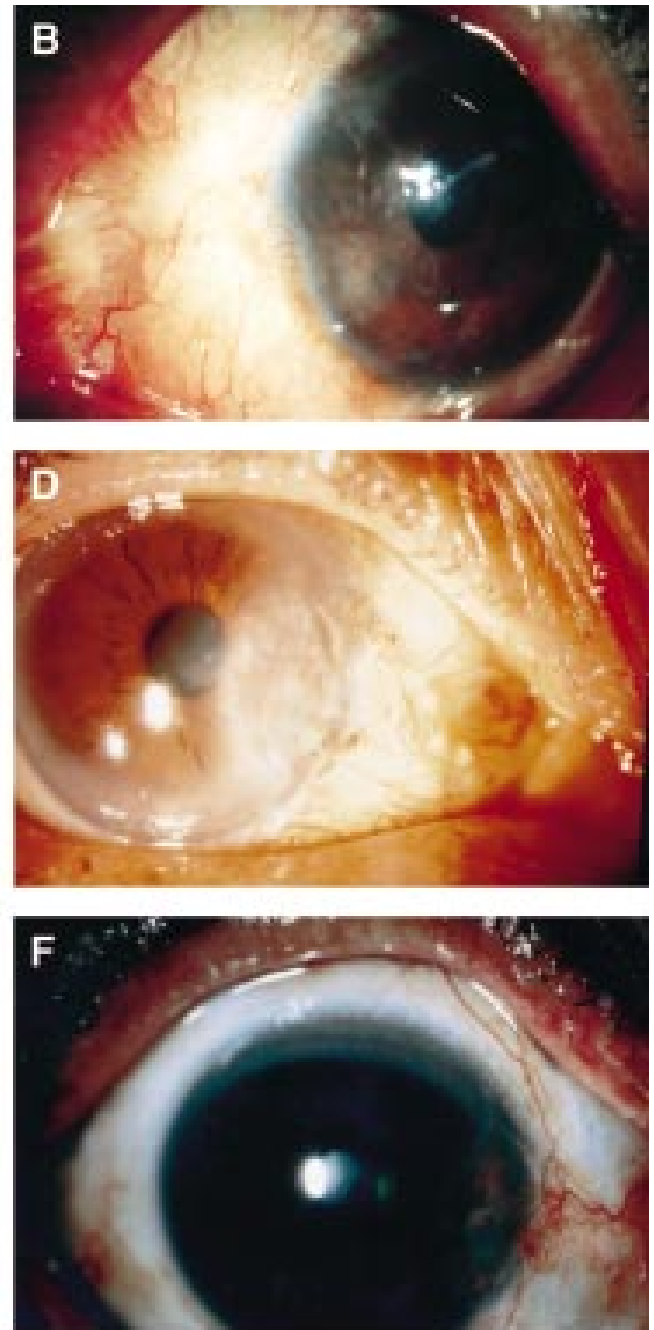
pterygium was blocked by the lamellar graft, massive subconjunctival fibrosis caused severe diplopia and foreign body sensation (Fig 2G). We treated the patient in January 1996 with a combination of total fibrous tissue removal, amniotic membrane transplantation and a limbal autograft, and fornix reconstruction including placement of a silicone sponge. Six months after surgery, the patient's vision was $20 / 15$, and pterygium had not recurred. Slight subconjunctival fibrosis at the 10 o'clock bulbar conjunctiva remained, but diplopia was greatly diminished (Fig $2 \mathrm{H})$.

\section{Discussion}

EFFECTS OF AMNIOTIC MEMBRANE

TRANSPLANTATION FOR RECURRENT PTERYGIUM

We treated four patients with recurrent pterygium associated with symblepharon with amniotic membrane transplantation and a limbal autograft. In addition to preventing invasion of subconjunctival tissue into the cornea, this procedure successfully suppressed the regrowth of subconjunctival fibrosis. The surgical area of the conjunctiva was flat after surgery, with minimal scarring. These results differ from those of other surgical methods such as keratoepithelioplasty or lamellar keratoplasty, for example, in which the transplanted grafts serve as barriers to fibrous tissue invasion, and subconjunctival fibrosis is virtually inevitable. ${ }^{347}$ Suppression of subconjunctival fibrosis was essential in the cases presented since all patients suffered from limited ocular movement. Amniotic membrane transplantation appeared to be effective in restoring ocular motility.

USE OF AMNIOTIC MEMBRANE AND ITS

CHARACTERISTICS

Amniotic membrane has been used for treating leg ulcers, ${ }^{15}$ skin loss in Stevens-Johnson syndrome, ${ }^{21}$ and in pelvic and vaginal surgery. ${ }^{22}{ }^{23}$ It has also been used as temporary skin dressing in burns, ${ }^{182425}$ and surgical wounds. ${ }^{26}$ In the field of ophthalmology, amniotic membrane transplantation was originally used in the 1940s for conjunctival defects. ${ }^{27-29}$ Recently, the technique has been revised for the treatment of ocular cicatricial pemphigoid, Stevens-Johnson syndrome, chemical burns, ${ }^{30}{ }^{31}$ and persistent epithelial defects. ${ }^{32}$

Amniotic membrane has unique properties including antiadhesive effects, antibacterial effects, wound protection, pain reduction, and epithelialisation effects. ${ }^{15-18}$ 21-26 Its antiadhesion property was striking in our four patients where severe symblepharon was lysed almost completely. Amniotic membrane is composed mainly of a thick collagen layer and overlying basement membrane components including laminin and type IV collagen. ${ }^{33}$ The probable mechanism of this effect is contact with normal substrates; contact with healthy tissue induces an arrest in tissue proliferation. In addition, the amniotic membrane transplant may also function as an anamical barrier to fibrous tissue proliferation. Another unique characteristic of amniotic membrane is its lack of immunogenicity; the tissue does not express the usual major histocompatibility antigens-for example, HLA-A, B, or DR. ${ }^{34-36}$ As a result, amniotic membrane does not induce immunological rejection after its transplantation. The membrane, especially the epithelium, also produces various growth factors including basic fibroblast growth factor, hepatocyte growth factor, and transforming growth factor $\beta$ (unpublished data). Our preliminary data suggest that epithelium of the amniotic membrane survives for up to 70 days after preservation. The growth factors may modulate the differentiation and proliferation of conjunctival and corneal cells. Although the exact mechanism is unknown, its unique characteristics make the amniotic membrane a suitable material for treating subconjunctival fibrosis.

\section{COMPARISON WITH OTHER SURGICAL METHODS}

For covering the exposed sclera with a free graft after pterygium excision, the conjunctiva is probably the most suitable material. ${ }^{12}$ However, suppression of subepithelial fibrosis may not be achieved by a conjunctival graft alone. ${ }^{7}$ In addition, owing to its limited availability, conjunctiva cannot be used to cover the entire area when extensive fibrous tissue exists.

Buccal or nasal mucosa and nasal mucosa transplants have also been used for severe conjunctival injuries. ${ }^{37}{ }^{38}$ Since these tissues contain subepithelial mucous glands, they can be used to supply mucin in patients with mucus deficiency syndrome. The mechanism of amniotic membrane transplantation is different from that of buccal and nasal mucosa transplantation; the transplanted epithelium of the buccal and nasal grafts survives after surgery, functioning as a substitute for conjunctival epithelium. In contrast, the transplanted amniotic membrane is covered by conjunctival epithelium and serves as a new substrate for proper epithelialisation. The need for further surgical intervention, the persistence of reddish coloration long after surgery, and the limited size of the grafts are disadvantages of buccal or nasal mucosa transplantation. ${ }^{38}$ In contrast, amniotic membrane can be used to cover areas of almost any size, and its appearance is almost indistinguishable from the area outside the membrane.

Use of antimetabolites, especially intraoperative administration of MMC, may be performed in conjunction with amniotic membrane transplantation. Covering bare sclera with amniotic membrane may decrease the risk of scleral ulcer formation as a late complication with the use of antimetabolites. ${ }^{1314}$ As the amniotic membrane may function as a drug delivery system, drug concentration, and duration of its administration should be further determined.

\section{FUNCTION OF LIMBAL AUTOGRAFT}

TRANSPLANTATION

Limbal autografts have been used in treating monocular chemical or thermal burn, aniridia, conjunctival squamous cell carcinoma, recurrent or advanced pterygia, and contact lens associated ocular surface abnormality. ${ }^{63940}$ Limbal autografts have been used successfully to correct limbal dysfunction, acting as a 
barrier against conjunctival invasion of the cornea and supplying stem cells of the corneal epithelium. In treating chemical burns and other traumatic conditions, the limbal grafts are obtained from the unaffected eye. In our patients, however, the limbal grafts were obtained from the affected eye. ${ }^{6}$ This type of limbal transplantation does not weaken total limbal function; instead it transfers healthy limbus to the affected area. Indeed, no complications at the donor sites, such as pseudopterygium formation, were observed in our series. In the one patient who developed slight postoperative recurrence, subconjunctival tissue did not override the limbal graft, but invaded beneath it. We believe that a limbal graft need not necessarily cover the entire area of excision. Our limbal and conjunctival grafts measured about $4 \times 4 \mathrm{~mm}$ in each case. Use of small limbal grafts may lessen concerns about adverse postoperative consequences in the donor area. Simultaneous limbal autograft transplantation may not be necessary in less severe cases; however, a recent study reported that amniotic membrane transplantation alone resulted in further recurrence in $37.5 \%$ of eyes treated for recurrent pterygium. ${ }^{41}$

In summary, we have found that the combination of an amniotic membrane transplant to inhibit subconjunctival fibrosis, and a limbal autograft to restore limbal function is an effective surgical procedure for treating patients with recurrent pterygium associated with severe symblepharon.

1 Kenyon KR, Wagoner MD, Hettinger ME. Conjunctival autograft transplantation of advanced and recurrent pterygium. Ophthalmology 1985;92:1461-70.

2 Riordan-Eva P, Kielhorn I, Ficker LA, McG Steele AD Kirkness CM. Conjunctival autografting in the surgica management of pterygium. Eye 1993;7:634-8.

3 Thoft RA. Keratoepithelioplasty. Am $\mathcal{F}$ Ophthalmol 1984;97: $1-6$.

4 Pearlman G, Susal AL, Hushaw J, Bartlett RE. Recurrent pterygium and treatment with lamellar keratoplasty with pterygium and treatment with lamellar keratoplasty with nary report. Ann Ophthalmol 1970;2:763-71.

5 Pfister RR. Corneal stem cell disease: concepts, categorizaPfister RR. Corneal stem cell disease: concepts, categoriza-
tion, and treatment by auto- and homotransplantation of tion, and treatment by auto- and homotran

6 Shimazaki J, Yang H-Y, Tsubota K. Limbal autograft transplantation for recurrent and advanced pterygia. Ophthalmic Surg Lasers 1996;27:917-23.

7 Vrabec MP, Weisenthal RW, Elsing SH. Sunconjunctival fibrosis after conjunctival autograft. Cornea 1993;12:1813.

8 Hayasaka S, Noda S, Yamamoto Y, Setogawa T. Postoperative instillation of low-dose mitomycin C in the treatment of promary pterygium. Am $\mathcal{f}$ Ophthalmol 1988;106:715-8.

9 Frucht-Pery J, Ilsar M. The use of low-dose mitomycin C for prevention of recurrent pterygium. Ophthalmology for prevention of

10 Frucht-Pery J, Ilsar M, Hemo I. Single dosage of mitomycin-C for prevention of recurrent pterygium: mitomycin-C for prevention of recurre

11 Cardillo JA, Alves MR, Ambrosio LE, Poterio MB, Jose NK. Single intraoperative application versus postoperative Single intraoperative application versus postoperative
mitomycin C eye drops in pterygium surgery. Ophthalmolmitomycin C eye drops

12 Mastropasqua L, Carpineto P, Ciancaglini M, Gallenga PE. Long term results of intraoperative mitomycin $\mathrm{C}$ in the treatment of recurrent pterygium. $\mathrm{Br} F$ Ophthalmol 1996;80:288-91.

13 Dunn JP, Seamore CD, Ostler HB, Nickel BL, Beallo A Development of scleral ulceration and cacification after pterygium excision and mitomycin therapy. Am f Ophthalmol 1991:112:343-4.

14 Rubinfeld RS, Pfister RR, Stein RM, et al. Serious complications of topical mitomycin-C after pterygium surgery. Ophthalmology 1992;99:1647-54.

15 Trelford JD, Trelford-Sauder M. The amnion in surgery, past and present. Am f Obstet Gynecol 1979;134:833-45.

16 Rennekampff H-O, Dohrmann P, Föry R, Fändrich F. Evaluation of amniotic membrane as adhesion prophylaxis in a novel surgical gastroschisis model. Invest Surg 1994;7: 187-93.

17 Tayyar M, Turan R, Ayata D. The use of amniotic membrane plus heparin to prevent postoperative adhesions in the rabbit. Tokai f Exp Clin Med 1993;18:57-60.

18 Colocho G, Graham WP, Greene AE, Matheson DW, Lynch D. Human amniotic membrane as a physiologic wound dressing. Arch Surg 1974;109:370-3.

$19 \mathrm{Li} \mathrm{E}$, Tseng SCG. Three patterns of cytokine expression potentially involved in epithelial-fibroblast interactions of human ocular surface. f Cell Physiol 1995;163:61-79.

20 Kim JC, Tseng SCG. Transplantation of preserved human amniotic membrane for surface reconstruction in severely damaged rabbit corneas. Cornea 1995;14:472-84.

21 Prasad JK, Feller I, Thompson PD. Use of amnion for the treatment of Stevens-Johnsons syndrome. F Trauma 1986; 26:945-6.

22 Tancer ML, Katz M, Perez-Verdidiano N. Vaginal epithelialization with human amnion. Obstet Gynecol 1979;52:198204.

23 van der Linden PJ, de Goeij AF, Dunselman GA, Erkens HW, Evers JL. Endometrial cell adhesion in an in vitro model using intact amniotic membranes. Fertil Steril 1996; 65:76-80.

24 Subrahmanyam M. Amniotic membrane as a cover for microskin grafts. Br f Plast Surg 1995;48:477-8.

25 Talmi YP, Finckelstein Y, Zohar Y. Use of human amniotic membrane as a biologic dressing. Eur F Plast Surg 1990;13: $160-2$.

26 Zohar Y, Talmi YP, Finckelstein Y, et al. Use of human amniotic membrane in otolaryngologic practice. Laryngoscope 1987;97:978-80.

27 de Rötth A. Plastic repair of conjunctival defects with fetal membranes. Arch Ophthalmol 1940;23:522-5.

28 Lavary W. Lime burns of conjunctiva and cornea treated with amnioplastin graft. Trans Ophthalmol Soc UK 1946;66: $668-71$.

29 Sorsby A, Haythorne J, Reed H. Amniotic membrane grafts in caustic soda burns. Br F Ophthalmol 1947;31:401-4.

30 Tsubota K, Satake Y, Ohyama M, et al. Surgical reconstruction of the ocular surface in advanced ocular cicatricial pemphigoid and Stevens-Johnson syndrome. $A m \mathcal{F} O p h$ thalmol 1996;122:38-52

31 Shimazaki J, Yang H-Y, Tsubota K. Amniotic membrane transplantation for ocular surface reconstruction in patients with chemical and thermal burns. Ophthalmology (in press).

32 Lee S-H, Tseng SCG. Amniotic membrane transplantation for persistent epithelial defects with ulceration. Am f Ophthalmol 1997;123:303-12.

33 van Herendael BJ, Oberti C, Brosens I. Microanatomy of the human amniotic membrane: a light microscopic, transmission, and scanning microscopic study. Am $\mathcal{f}$ Obstet Gynecol 1978;131:872-80.

34 Adinofli M, Akle CA, McColl I, et al. Expression of HLA antigens, $\beta_{2}$-microglobulin and enzymes by human amniotic membrane. Nature 1982;295:325-7.

35 Akle CA, Adinolfi M, Welsh KI, Leibowitz S, McColl I. Immunogenicity of human amniotic epithelial cells after transplantation into volunteers. Lancet 1981;ii:1003-5.

36 Houlihan JM, Biro PA, Harper HM, Jenkinson HJ, Holmes $\mathrm{CH}$. The human amniotic membrane is a site of MHC class $1 \mathrm{~b}$ expression: evidence for the expression of HLA-E and HLA-G. I Immunol 1995;154:5665-74.

37 Siegel A. Buccal mucous membrane graft in burns. Arch Ophthalmol 1944;32:104-8.

38 Naumann GOH, Lang GK, Rummelt V, Wigand ME. Autologous nasal mucosa transplantation in severe bilateral conjunctival mucus deficiency syndrome. Ophthalmology 1990;97:1011-7

39 Kenyon KR, Tseng SCG. Limbal autograft transplantation for ocular surface disorders. Ophthalmology 1989;96:70922

40 Copeland RA, Char DH. Limbal autograft reconstruction after conjunctival squamous cell carcinoma. Am $\mathcal{f}$ Ophthalmol 1990;110:412-5.

41 Prabhasawat P, Barton K, Burkett G, Tseng SCG. Comparison of conjunctival autograft, amniotic membrane grafts, and primary closure for pterygium excision. Ophthalmology 1997;104:974-85. 